\title{
Modulation of neuronal survival factor MEF2 by kinases in Parkinson's disease
}

\author{
Yue Yin ${ }^{1,2,3}$, Hua She ${ }^{2,3}$, Wenming Li $^{2,3}$, Qian Yang ${ }^{2,3}$, Shuzhong Guo ${ }^{1}$ and Zixu Mao ${ }^{2,3}$ * \\ 1 Institute of Plastic Surgery, Xijing Hospital, Fourth Military Medical University, Xi'an, Shaanxi, China \\ 2 Department of Pharmacology, Emory University School of Medicine, Atlanta, GA, USA \\ ${ }^{3}$ Department of Neurology, Emory University School of Medicine, Atlanta, GA, USA
}

Research Topic: From structural to molecular systems biology: experimental and computational approaches to unravel mechanisms of kinase activity regulation in cancer and neurodegeneration

\section{Edited by:}

Matteo Barberis, Humboldt University

Berlin, Germany; Max Planck Institute

for Molecular Genetics, Berlin,

Germany

\section{Reviewed by:}

Noriko Hiroi, Keio University, Japan Anatoly Sorokin, The Institute of Cell

Biophysics RAS, Russia

\section{${ }^{*}$ Correspondence:}

Zixu Mao, Departments of

Pharmacology and Neurology, Emory University School of Medicine,

Whitehead Building, Room 565, 615

Michael Street, Atlanta, GA 30322,

USA.

e-mail: zmao@pharm.emory.edu
Parkinson's disease (PD) is the second most common neurodegenerative disorder due to selective death of neurons in the substantia nigra pars compacta. The cause of cell death remains largely unknown. Myocyte enhancer factor 2 (MEF2) is a group of transcriptional factors required to regulate neuronal development, synaptic plasticity, as well as survival. Recent studies show that MEF2 functions are regulated in multiple subcellular organelles and suggest that dysregulation of MEF2 plays essential roles in the pathogenesis of PD. Many kinases associated with transcription, translation, protein misfolding, autophagy, and cellular energy homeostasis are involved in the neurodegenerative process. Following the first demonstration that mitogen-activated protein kinase p38 (p38 MAPK) directly phosphorylates and activates MEF2 to promote neuronal survival, several other kinase regulators of MEF2s have been identified. These include protein kinase A and extracellular signal regulated kinase 5 as positive MEF2 regulators, and cyclin-dependent kinase 5 (Cdk5) and glycogen synthase kinase $3 \beta$ as negative regulators in response to diverse toxic signals relevant to PD. It is clear that MEF2 has emerged as a key point where survival and death signals converge to exert their regulatory effects, and dysregulation of MEF2 function in multiple subcellular organelles may underlie PD pathogenesis. Moreover, several other kinases such as leucine-rich repeat kinase 2 and PTEN-induced putative kinase 1 (PINK1) are of particular interest due to their potential interaction with MEF2.

\section{INTRODUCTION}

Parkinson's disease $(\mathrm{PD})$ is the second most common neurodegenerative disorder after Alzheimer's disease (AD). Clinically PD is characterized by resting tremor, bradykinesia, rigidity, and balance difficulty, mostly along with autonomic abnormalities, psychiatric disturbance, cognitive impairment, and dementia. Pathologically, it is clear that PD results from the massive death of dopaminergic (DA) neurons in the substantia nigra pars compacta (SNpc) region. However, the causes of such selective neuronal death in PD remain unknown. Current PD medication and therapy treat only symptoms and cannot prevent or delay neuronal death (Dauer and Przedborski, 2003). Our very limited understanding of mechanisms by which neurodegeneration is triggered constitutes the main obstacle for the development of effective therapeutics to cure this devastating disease. In spite of this, several risk factors associated with the disease have been identified. Like other neurodegenerative diseases, aging is generally considered to be the greatest risk factor for PD (Lees et al., 2009). Exposure to environmental toxins, such as herbicides, pesticides, lead, manganese, welding, 1-methyl-4-phenyl-1,2,3,6-tetrahydropyridine (MPTP), cyanide, carbon disulfide, and toluene, may produce similar but not identical clinical features (Tanner and Aston, 2000; Elbaz and Moisan, 2008). It is also been reported that head injury, well-water ingestion, rural living, middle-age obesity, and lack of exercise may have association with PD (Elbaz and Tranchant, 2007; Thacker et al., 2008). Recently, genetic studies have made great breakthrough in etiology of PD, revealing several genes that are closely linked to heritable PD, which accounts for about 10\% PD cases (Paisán-Ruíz et al., 2004; Valente et al., 2004; Zimprich et al., 2004; Seki et al., 2011). How these different factors may function together in triggering PD remains unclear. Some researchers contend that aging induces a pre-parkinsonian state, and that during normal aging the cellular mechanisms of dopamine neuron demise are accelerated or exaggerated through a combination of genetic and environmental factors (Collier et al., 2011).

Identified initially in muscle cells, myocyte enhancer factor 2 (MEF2) is a member of the MCM1-agamous-deficiens-serum response factor (MADS) family of transcription factors (Yu et al., 1992). There are four members of MEF2 genes, MEF2A-D. Although MEF2 was originally discovered in muscle cells to promote the expression of many muscle specific genes, they were late found to be expressed in other tissues and cell types. For example, MEF2s have been shown to participate in immune cell response, glucose metabolism in adipocytes, angiogenesis, liver fibrosis, as well as many essential molecular events in CNS such as neuronal development, synaptic plasticity, and survival (Leifer et al., 1993; Mao et al., 1999). More importantly, the loss of MEF2D-mediated neuronal survival has been shown to underlie the process of the survival of DA neurons in models of PD (Gong et al., 2003; Smith et al., 2006). More recent findings have revealed several 
novel molecular mechanisms by which MEF2D may underlie the pathogenic process of PD (Yang et al., 2009; She et al., 2011).

As a critical survival protein, MEF2s are tightly regulated via posttranslational modification. It is known that phosphorylation by kinases is an important process through which the activity of MEF2 is up- or down-regulated. Several kinases have been linked to neuronal survival in part due to their modulation of MEF2 function. Following the report that lipopolysaccharide (LPS) increases the transactivation activity of MEF2C through phosphorylation by p38 MAPK in monocytic cells during infection (Han et al., 1997), MEF2 has been found to be activated by p38 in neurons to promote neuronal survival (Mao et al., 1999). Other kinases including protein kinase A (PKA), extracellular signal regulated kinase 5 (ERK5), Cdk5, and glycogen synthase kinase $3 \beta$ (GSK3 $\beta$ ), have subsequently been identified as regulators of MEF2 in neurons (Gong et al., 2003; Liu et al., 2003; Wang et al., 2005, 2009).

Recent advances have revealed several genes whose alternations have been associated with familial PD. These include genes for SNCA, UCHL1, GIGYF2, HtrA2, LRRK2, PARK2, DJ1, PINK1, and ATP13A2 (Kim and Choi, 2010; Seki et al., 2011). Leucinerich repeat kinase 2 (LRRK2) and PINK1 are of particular interest because they are kinases and known to be involved in autophagy and mitophagy, two processes to which MEF2D have been linked (Paisán-Ruíz et al., 2004; Valente et al., 2004; Zimprich et al., 2004). This raises the possibility that these two kinases may modulate MEF2 function directly or indirectly in neurons.

\section{THE POSITIVE MEF2 REGULATORS: p38, PKA, ERK5, AND mTOR}

\section{p38: PHOSPHORYLATION OF MEF2 BY p38}

p38 MAPK, which includes four different but functionally overlapping isoforms (p38 $\alpha, \mathrm{p} 38 \beta, \mathrm{p} 38 \gamma$, and p38 $)$ ), is a class of MAPK family that is responsible to stress stimuli and involved in cell differentiation and apoptosis (Han et al., 1994; Li et al., 1996; Mertens et al., 1996; Jiang et al., 1997). p38 was first identified in studies of endotoxin-induced cell activation, which showed that p38 was tyrosine phosphorylated after extracellular changes in osmolarity in response to LPS (Han et al., 1993, 1994). p38 can be activated by diverse extra/intracellular stimuli and various cellular stressors (Raingeaud et al., 1995; Xia et al., 1995; Graves et al., 1996). In SH-SY5Y cells, rotenone-induced cell death requires the activation of p38 while expression of dominant interfering form of p38 attenuates rotenone-induced apoptosis (Newhouse et al., 2004).

In response to physical-chemical stresses and proinflammatory cytokines, p38 specifically phosphorylates Ser 387, Thr 293, and Thr 300 within the MEF2C transactivation domain (Raingeaud et al., 1995; Han et al., 1997). Similarly, it has been demonstrated that under stimulation by UV light or interleukin-1 (IL-1), MEF2A can also be phosphorylated by p38 at several key regulatory sites such as Ser 383, Thr 312, and Thr 319, leading to enhanced transcriptional activity of MEF2A (Yang et al., 1999; Zhao et al., 1999). One study reported that MEF2D is not phosphorylated by $\mathrm{p} 38$ as a substrate (Zhao et al., 1999). Since MEF2D can dimerize with MEF2A, it was proposed that phosphorylation of MEF2A by $\mathrm{p} 38$ in the MEF2A and MEF2D complex may potentially up-regulate MEF2-dependent gene expression (Zhao et al., 1999). However, Rampalli et al. (2007) found that the phosphorylation of MEF2D requires p38 signaling pathway and inhibition of p38 markedly reduces MEF2D activity and target genes in mouse myoblast cells.

After the initial description that LPS regulated MEF2 via p38, several studies started to focus on the role of p38-MEF2 in neurons. Calcium functions as a second messenger mediating a wide range of cellular responses in neurons (Ghosh and Greenberg, 1995). It was shown that calcium influx into cerebellar neurons triggered by extracellular stimuli induces activation of p38, leading to p38dependent and direct phosphorylation of MEF2C at Ser 387 (Han et al., 1997; Mao et al., 1999). These findings, taken together, suggest that calcium influx into neurons results in activation of the MKK6-p38 cascade and phosphorylation and activation of MEF2 by 38.

Further studies showed that blocking the p38 signaling pathway promotes apoptosis of differentiating neurons (Mao et al., 1999; Okamoto et al., 2000). In cerebellar granule neurons (CGNs), dominant-negative interfering forms of $\mathrm{p} 38$ reduced neuronal viability by inhibiting the activity of MEF2. Increasing MEF2 activity by expressing a constitutively active form of MEF2 in neurons attenuated neuronal death induced by dominant-interfering p38 (Mao et al., 1999). These observations indicate that MEF2 protects neurons from apoptosis in a p38 pathway-dependent manner.

\section{PKA: PHOSPHORYLATION OF MEF2 BY PKA}

It is known that neurons which receive insufficient trophic support will undergo apoptotic death (Oppenheim, 1991). Rydel et al. reported that cyclic AMP (cAMP) could replace nerve growth factor (NGF), one of the neurotrophic factors, in promoting longterm survival in cultured rat neonatal sympathetic and embryonic sensory neurons (Rydel and Greene, 1988). cAMP-mediated neuronal survival requires the activation of cAMP-dependent protein kinase (Rydel and Greene, 1988). One such major downstream effector for cAMP is PKA.

Cerebellar granule neurons cultured in the presence of a high concentration of extracellular $\mathrm{KCl}(25-30 \mathrm{mM})$ can survive in the absence of serum or other additional growth factors due to high concentration of $\mathrm{KCl}$-induced membrane depolarization while low concentration of $\mathrm{KCl}$ induces CGN apoptosis (Franklin and Johnson, 1992; D'Mello et al., 1993; Miller et al., 1997). Our studies showed that in this model, cAMPPKA pathway enhances MEF2-dependent DNA binding and gene expression and promotes membrane depolarization-induced neuronal survival (Wang et al., 2005). Blocking PKA activity with two widely used kinase inhibitors, H89, and myristoylated PKI, causes a concentration- and time-dependent loss of neuronal viability. Based on the results of luciferase reporter gene assay, high MEF2 activity is associated with membrane depolarizationdependent survival, whereas apoptosis induced by low concentration of $\mathrm{KCl}$ correlates with decreased MEF2 function. More importantly, PKA could directly phosphorylate MEF2C at Thr 20, which enhanced MEF2 DNA binding activity (Wang et al., 2005). Together, these findings indicate that in response to membrane depolarization, cAMP-PKA pathway stimulates MEF2 activity by direct phosphorylation to promote neuronal survival.

\section{ERK5: PHOSPHORYLATION OF MEF2 BY ERK5}

Over a decade ago, ERK5, also known as the big MAP kinase 1 (BMK1), was discovered as a new member of MAP kinase 
family (Lee et al., 1995; Zhou et al., 1995). Similar to the other two ERK group members, ERK1 and ERK2, ERK5 has a TEY dual-phosphorylation motif but it possesses an unusual large $\mathrm{C}$ terminus and a unique loop-12 sequence which distinguish it from ERK1/2 (Lee et al., 1995). ERK5 is activated exclusively by its upstream activator MAPK/ERK kinase 5 (MEK5), which does not phosphorylate ERK1/2, c-Jun N-terminal protein kinase (JNK), or p38 (English et al., 1995; Zhou et al., 1995). Subsequent studies showed that the MEK5/ERK5 signaling pathway is involved in cell survival, anti-apoptotic signaling, angiogenesis, cell motility, differentiation, and cell proliferation (Liu et al., 2003; Hayashi et al., 2005; Roberts et al., 2009).

As an important kinase activating numerous substrates, ERK5 has been found to phosphorylate a number of downstream targets including MEF2 (Kato et al., 1997; English et al., 1998; Yang et al., 1998; Marinissen et al., 1999). Previous work demonstrated that ERK5 specifically phosphorylated MEF2C at Ser 387 in response to serum stimulation, which greatly enhances the transactivation activity of MEF2C, leading to increased MEF2Cdependent gene expression (Kato et al., 1997). In contrast to p38, further studies indicated that ERK5 also phosphorylates MEF2A and MEF2D. Interestingly, phosphorylation by ERK5 was shown to enhance the transcriptional activity of MEF2A but did not appear to affect MEF2D activity (Yang et al., 1998).

Extracellular signal regulated kinase 5 is widely expressed in many cell lines and tissues including a high level in the brain (Liu et al., 2003; Yan et al., 2003; Buschbeck and Ullrich, 2005). It has been reported that ERK 5 can be activated by epidermal growth factor, $\mathrm{G}$ protein-coupled receptors, and neurotrophins (NTs) which include NGF, brain-derived neurotrophic factor (BDNF), NT3, NT4/5, and NT6 (Segal and Greenberg, 1996; Kato et al., 1998; Kamakura et al., 1999; Marinissen et al., 1999). MEF2C is a wellestablished substrate of ERK5 in cortical neurons from postnatal day 0 rats (Cavanaugh et al., 2001). Subsequent work has shown that regulation of MEF2C by activated ERK5 under BDNF or NT seems to be functionally relevant to the survival of developing cortical neurons but not mature neurons (Liu et al., 2003; Shalizi et al., 2003). In primary cortical neurons cultured from embryonic day 17 (E17) rats, ERK5 activity mediates the neuroprotective function of BDNF by phosphorylating and activating MEF2. Blocking either ERK5 activity or MEF2 transcription significantly reduces BDNF protection against trophic withdrawal in E17 neurons (Liu et al., 2003).

Oxidative damage contributes to the neurodegenerative process and plays a role in PD pathogenesis (Dexter et al., 1989; Alam et al., 1997a,b; Pearce et al., 1997; Floor and Wetzel, 1998; Sherer et al., 2003). Suzaki et al. (2002) firstly reported that oxidative stress such as $\mathrm{H}_{2} \mathrm{O}_{2}$ leads to protective activation of ERK5 in PC12 cells, leading to an enhancement of DNA binding activity of MEF2. Attenuating this enhancement by the MEK1/2 inhibitors, U0126 and PD98059, which have been reported to inhibit MEK5 also (Kamakura et al., 1999), significantly augments the $\mathrm{H}_{2} \mathrm{O}_{2}$-induced cell death (Suzaki et al., 2002). These findings suggest that regulation of MEF2 by ERK5 exerts anti-apoptotic function against oxidative stress.

\section{mTOR: A POTENTIAL REGULATOR OF MEF2}

Mammalian target of rapamycin (mTOR), also known as FK506 binding protein 12-rapamycin associated protein 1 (FRAP1), is a serine/threonine protein kinase belonging to the phosphatidylinositol 3-kinase (PI3K)-kinase-related kinase (PIKK) superfamily (Kunz et al., 1993; Brown et al., 1994; Chiu et al., 1994; Sabatini et al., 1994; Chen et al., 1995; Domin and Waterfield, 1997). mTOR functions as at least two complexes, mTORC1 and mTORC2, which consist of mTOR and unique mTOR-interacting proteins, playing important roles in signaling network of cells (Hara et al., 2002; Kim et al., 2002; Fingar and Blenis, 2004; Jacinto et al., 2004; Sarbassov et al., 2004, 2006; Hresko and Mueckler, 2005; Zhou and Huang, 2010). Raptor, an mTORC1 protein, can bind to $\mathrm{p} 70 \mathrm{~S} 6 \mathrm{~K}$ and eukaryotic initiation factor $4 \mathrm{E}$-binding protein 1 (4EBP1), the two best-characterized mTOR downstream targets (Hara et al., 2002; Kim et al., 2002; Zhou and Huang, 2010). By sensing growth factor, mitogen, energy, and nutrient signals, mTORC1 participates in regulation of cell growth, proliferation, and survival (Fingar and Blenis, 2004; Chong et al., 2010; Zhou and Huang, 2010). The activation pathway of mTORC2 is still far from being clearly elucidated. However, it has been reported that mTORC2 lies downstream of PI3K and Akt to modulate cell survival in response to growth factor (Hay and Sonenberg, 2004; Jacinto et al., 2004; Hresko and Mueckler, 2005; Sarbassov et al., 2006; Chong et al., 2010; Zhou and Huang, 2010).

Mammalian target of rapamycin also plays a central role in the crossroads of different pathways regulating macroautophagy, also called mTOR-dependent autophagy (Pattingre et al., 2008). Recent studies have showed that ischemic brain injury induces a decrease in phospho-mTOR and phospho-p70S6, which contributes to neuronal death (Koh, 2008; Koh et al., 2008). Based on these results, we then investigated the interaction between mTOR/p70S6K pathway and MEF2D, and revealed the function of $\mathrm{mTOR} / \mathrm{p} 70 \mathrm{~S} 6 \mathrm{~K}$ in regulating ischemic or hypoxia-induced MEF2D autophagy and neuronal death (Tian et al., unpublished data).

Mammalian target of rapamycin pathway has been shown to regulate MEF2 in non-neuronal cells (Xu and Wu, 2000). mTOR pathway plays a critical role in cellular autophagy (Jung et al., 2010). Our recent work demonstrated that chaperone-mediated autophagy (CMA) modulates neuronal survival machinery by regulating MEF2D in neurons. This regulation is sensitive to the level of nutrients and to the levels of $\alpha$-synuclein (Yang et al., 2009). Together, these findings suggest that mTOR may directly regulate MEF2 in neurons in response to stress.

\section{THE NEGATIVE MEF2 REGULATORS: Cdk5 AND GSK3 $\beta$ Cdk5: PHOSPHORYLATION-INDUCED DEGRADATION OF MEF2}

Two decades ago, a new member of cyclin-dependent kinase (Cdk) family, Cdk5, was discovered (Hellmich et al., 1992; Lew et al., 1992; Meyerson et al., 1992). The amino acid sequence of Cdk5 has up to $60 \%$ homology to that of human Cdk2 and cell division cycle kinase 2 (Cdc2; Hellmich et al., 1992). However, unlike other Cdk family members whose expression and activity fall to barely detectable levels at the end of cytogenetic period, Cdk5 is expressed in postmitotic neurons and appears to be inactive in dividing cells (Tsai et al., 1993; Grant et al., 2001). Cdk5 is activated by binding 
to its neural enriched activators, p35 and p39 (or their respective truncated forms, p25 and p29) or by phosphorylation (Lew et al., 1994; Tsai et al., 1994; Tang et al., 1995; Sharma et al., 1999; Zukerberg et al., 2000; Tanaka et al., 2001).

$\mathrm{Cdk} 5$ is regulated in neurons through extensive cross-talks with many signaling pathways (Ohshima et al., 1996; Chae et al., 1997; Smith et al., 2001; Fu et al., 2002; Zhu et al., 2011). Cdk5 is essential for a variety of neuronal functions and lack of Cdk5 function is destructive to CNS (Ko et al., 2001; Smith et al., 2001; Tanaka et al., 2001). In developing neurons, Cdk5 is critically involved in neuronal development via regulating axonal growth and path finding, neurite growth and/or spine morphogenesis, and neuronal migration. In the mature CNS, Cdk5 regulates multiple steps which are essential for synaptic plasticity, neurotransmitter synthesis, synaptic vesicle exocytosis, vesicle fusion, and endocytosis by phosphorylating a number of substrates (Zheng et al., 1998; Lagace et al., 2008; Zhu et al., 2011). Although lack of Cdk5 activity is detrimental to neurons, pathological overactivation of Cdk5 is also toxic to neurons, causing neuronal apoptosis under various pathological conditions (Ahuja et al., 1997; Zhang et al., 1997; Patrick et al., 1999; Gao et al., 2001).

One important mechanism by which overactivated Cdk5 triggers neuronal death is to inhibit the function of neuroprotective factor MEF2 (Gong et al., 2003). We first illustrated that Cdk5/p35 kinase complex regulated MEF2 by phosphorylating MEF2 at Ser 408a/444d (Ser 408 of MEF2A and Ser 444 of MEF2D) in neurons. Elevated Cdk5 activity inhibited MEF2 transactivation activity in cortical neurons and co-expression of Cdk5 and p25 led to even greater inhibition.

Neurotoxic insults including oxidative stress and excitotoxicity cause neuronal death and are widely believed to play a role in neurodegenerative processes including PD. Our analysis showed that in either cortical or CGNs, oxidative, and excitotoxic stresses markedly increase the kinase activity of Cdk5 in the nucleus. This is followed with a decline of MEF2D activity. Nuclear Cdk5 directly phosphorylates MEF2D at Ser 444. Phosphorylation of MEF2D at Ser 444 led clearly to destabilization of MEF2D and its activity (Gong et al., 2003). Inhibiting Cdk5 with roscovitine significantly blocked the phosphorylation of MEF2D at Ser 444 and rescued cortical and CGNs from excitotoxicity-induced deaths.

Our subsequent work revealed a novel mechanism by which phosphorylation of MEF2D by Cdk5 inhibits its activity. Excitotoxicity activates caspases in neurons. We demonstrated that phosphorylation of MEF2D by Cdk5 makes MEF2D a very good substrate for caspases, and its degradation by caspases (Tang et al., 2005). This degradation correlated with increased neuronal apoptosis. Inhibition of Cdk5 by a small molecule inhibitor roscovitine or increasing a form of MEF2D which cannot be phosphorylated by $\mathrm{Cdk} 5$ protected neurons from death, indicating that caspase-mediated MEF2 degradation is a critical mechanism underlying excitotoxicity and oxidative stress. In contrast to MEF2A and MEF2D, MEF2C is not phosphorylated by Cdk5 after glutamate exposure and, therefore, resistant to neurotoxin-induced caspase-dependent degradation, suggesting that such degradation is MEF2 isoform specific (Tang et al., 2005).

\section{GSK3 $\beta$ : DOWN-REGULATING MEF2D TRANSACTIVATION}

In 1980, a glycogen synthase kinase was partially purified from rabbit skeletal muscle and was named glycogen synthase kinase 3 (GSK3) to distinct from both cyclic-AMP-dependent protein kinase and phosphorylase (Embi et al., 1980; Rylatt et al., 1980). Sequence analysis revealed two gsk 3 genes, encoding two isoforms termed GSK3 $\alpha$ and GSK3 $\beta$ (Woodgett, 1990). GSK3 $\beta$ has two sites of phosphorylation, Ser 9 and Tyr 216, and phosphorylation at Ser 9 inhibits GSK3 $\beta$ activity while phosphorylation at Tyr 216 enhances its activity (Hughes et al., 1993; Cross et al., 1995). With its high level of expression in brain (Tung and Reed, 1989), GSK3 $\beta$ has been shown to play a prominent role in neuronal stress conditions such as in response to potassium deprivation and trophic withdrawal. Overexpression of it leads to caspase activation, neuronal loss, and gliosis (Pap and Cooper, 1998; Hetman et al., 2000; Lucas et al., 2001; Mora et al., 2001; Kaytor and Orr, 2002). Aberrant GSK3 $\beta$ activity had been associated with PD (Kwok et al., 2005; Kalinderi et al., 2011). However, the molecular mechanisms by which GSK3 $\beta$ mediates neuronal death require further elucidation.

Potassium-induced membrane depolarization is a widely used model of neuronal survival. In this model, potassium withdrawal induces CGNs to undergo synchronized apoptosis. It has been reported that in SH-SY5Y cells, GSK3 $\beta$ accumulates in the nuclei after serum withdrawal and this accumulation occurs early in the apoptotic process, preceding activation of caspases (Bijur and Jope, 2001). Based on these, we examined the regulation of MEF2D in CGNs following potassium withdrawal by GSK3 $\beta$ (Wang et al., 2009). Our analysis showed that potassium withdrawal causes a decrease in GSK3 $\beta$ protein in the cytoplasm of CGNs but an increase in the nuclei. This was accompanied by an elevation of nuclear GSK3 $\beta$ activity as shown by decreased inhibitory phosphorylation at Ser 9 (Wang et al., 2009). In vitro, GSK3 $\beta$ directly phosphorylated MEF2D. Mutation of amino acid residues Thr145, Ser149, and Ser 153 in combination led to a substantial attenuation of MEF2D phosphorylation by GSK3 $\beta$, suggesting that MEF2D is a GSK3 $\beta$ substrate. High level nuclear GSK3 $\beta$ activity correlated with a decline in MEF2 DNA binding and transcriptional activities. Over time, this decline also correlated with a decline in the levels of MEF2D protein (Wang et al., 2009). Blocking GSK3 $\beta$ activity by its inhibitor LiCl or SB216763 remarkably restored MEF2D level and activity, and prevented $\mathrm{KCl}$-induced CGN death. Moreover, overexpression of MEF2D T145A/S153A mutant, which was resistant to GSK3 $\beta$ phosphorylation, also reduced the number of apoptotic neurons during $\mathrm{KCl}$ deprivation. These findings suggest suggesting that inhibition of MEF2D by GSK3 $\beta$ pathway plays an essential role in mediating neuronal apoptosis caused by $\mathrm{KCl}$ withdrawal.

\section{OTHER KINASES RELATED TO PD LRRK2}

One of the most important advances in PD research in the past decade is the revelation of the genetic risk associated with PD, which has altered the previous concept that this age-related disease had little genetic component (Cookson, 2010). One of the genes found to be highly associated with familial PD is LRRK2, which encodes the protein leucine-rich repeat kinase 2 (Wider et al., 2010). Despite the fact that the physiologic functions of LRRK2 
protein are still poorly understood in neurons, the genetic evidence is clear that mutation of this gene causes familial PD (R1441C, Y1699C, G2019S, R1441G, R1441H, and I2020T), accounting for $1 \%$ of sporadic PD and 4\% of autosomal PD (Paisán-Ruíz et al., 2004; Zimprich et al., 2004; Healy et al., 2008; Devine et al., 2011; Drolet et al., 2011).

LRRK2 has been implicated in regulation of macroautophagy. It was found that overexpression of G2019S mutant LRRK2 in neuronal cells decreased neurite length and caused an accumulation of autophagic structures (MacLeod et al., 2006; Plowey et al., 2008; Ramonet et al., 2011). Similarly, overexpression of wild type LRRK2 in non-neuronal and yeast cells also led to an imbalance of macroautophagic process (Alegre-Abarrategui et al., 2009; Xiong et al., 2010). More recently, a study reported that LRRK2 activates the calcium-dependent protein kinase kinase- $\beta$ /adenosine monophosphate-activated protein kinase (AMPK) to increase macroautophagy (Gomez-Suaga et al., 2012). This appeared to require the function of the lysosomal $\mathrm{Ca}^{2+}$-mobilizing messenger nicotinic acid adenine dinucleotide phosphate (NAADP).

LRRK2 may also modulate autophagy by affecting $\alpha$-synuclein, encoded by one of the PD-related genes, SNCA. $\alpha$-synuclein is the main protein aggregated in Lewy Bodies, the intraneuronal inclusions in surviving neurons and pathologic hallmark of PD (Spillantini et al., 1997; Braak et al., 2003). It was reported that after transgenic mice with mutant human LRRK2 are crossed with mice over-expressing mutant human SNCA, accumulation of $\alpha$-synuclein is increased compared with mice over-expressing SNCA alone (Lin et al., 2009). In addition, over-expressing LRRK2 has been reported to accelerate the progression of $\alpha$-synucleinmediated neuropathology, promote the abnormal accumulation of $\alpha$-synuclein in cell bodies and the formation of $\alpha$-synuclein aggregates (Lin et al., 2009). Since $\alpha$-synuclein is known to be regulated by CMA as well as by macroautophagy (Williams et al., 2006; Vogiatzi et al., 2008) and to modulate CMA-dependent regulation of MEF2D in DA neurons (Yang et al., 2009), these findings raise an intriguing possibility that LRRK2 may act upstream of $\alpha$-synuclein and modulate MEF2 which may underlie in part the neurotoxicity caused by LRRK2 and play a role in the pathogenic process of $\mathrm{PD}$.

\section{PINK1}

When PTEN-induced putative kinase 1 (PINK1) was first identified, its abundant expression in heart, skeletal muscle, and testis but not brain offered little clue that this kinase could be connected to PD (Unoki and Nakamura, 2001). Soon after that, Valente et al. (2004) discovered two mutations in PINK1 gene affecting PINK1 kinase activity, which abrogates its protective effect on cells and is responsible for a form of heritable early onset PD. PINK1 localizes to mitochondria. Its loss of activity offers a molecular link between mitochondrial function and the pathogenesis of PD (Valente et al., 2004).

Shortly after the discovery that Parkin, whose gene mutation causes familial PD, can selectively promote the removal of damaged mitochondria by autophagy (mitophagy; Narendra et al., 2008), it was shown that PINK1 cooperatively regulate mitophagy with Parkin (Geisler et al., 2010; Matsuda et al., 2010; Narendra et al., 2010; Vives-Bauza et al., 2010). When mitochondrial membrane potential decreases, PINK1 is stabilized and accumulates selectively in dysfunctional mitochondria, allowing it to retrieve Parkin from the cytoplasm to the mitochondria where Parkin initiates the degradation of damaged mitochondria (Matsuda et al., 2010; Narendra et al., 2010). As an upstream effector, PINK1 is required by Parkin recruitment and Parkin-induced mitophagy because reducing PINK1 by PINK1 siRNA significantly blocks Parkin recruitment and mitophagy, suggesting that PINK1-Parkin pathway is a crucial mechanism by which mitophagy is mediated (Narendra et al., 2010; VivesBauza et al., 2010). This is relevant to PD since PINK1 mutation linked to PD disrupts mitophagy and respiratory chain, resulting in mitochondrial dysfunction and contributing to PD (Amo et al., 2011; Sato and Hattori, 2011). MEF2D is regulated by autophagy and has been shown to localize to mitochondria and regulate mitochondrial gene transcription, complex I activity of oxidative phosphorylation chain, and ATP production (She et al., 2011). Whether PINK1 and MEF2D pathway may cross-talk is an interesting open question and awaits further investigation.

\section{FUTURE PERSPECTIVES}

As discussed above, newly identified genes associated with familial forms of PD have provided powerful tools for us to delineate the

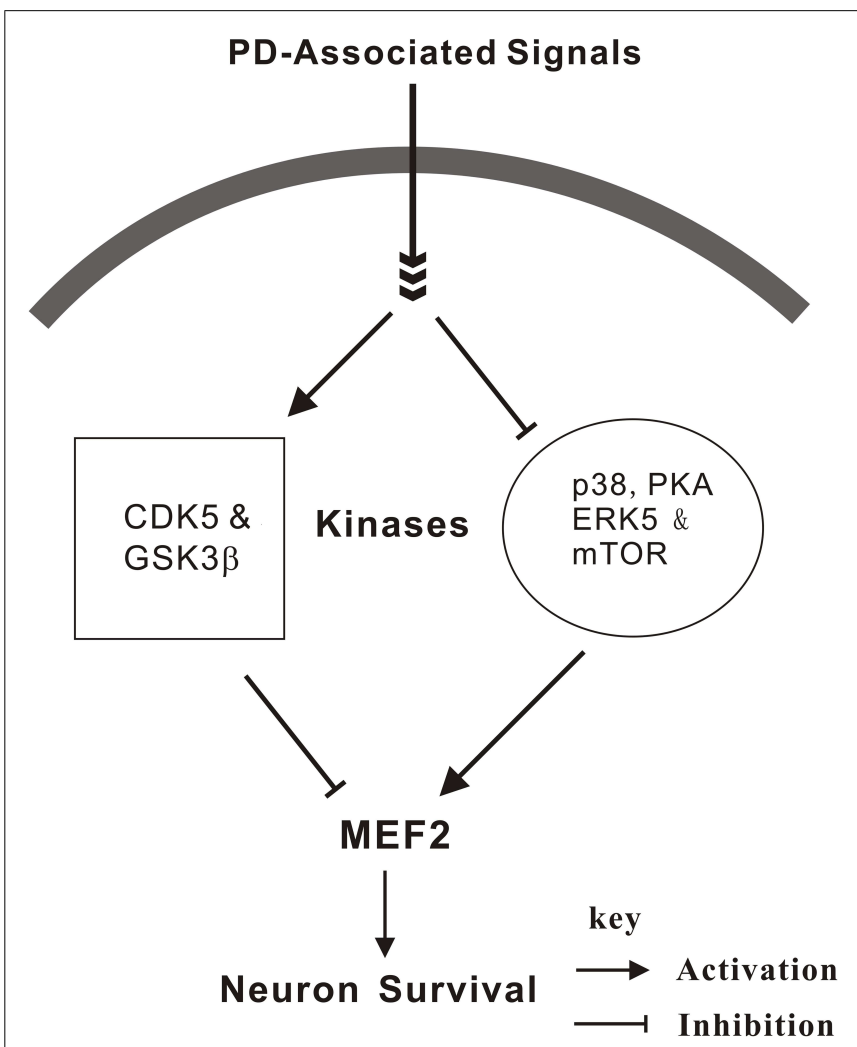

FIGURE 1 | Regulation of MEF2 by kinases in Parkinson's disease. MEF2 is a key point where survival and death signals converge to exert their regulatory effects. p38, PKA, ERK5, and mTOR have been identified as positive MEF2 regulators whereas $\mathrm{Cdk} 5$ and GSK3 $\beta$ are negative regulators in response to diverse toxic signals relevant to PD. 
molecular links underlying the key pathogenic processes in the disease. We have summarized some of the findings of key kinases whose activities have been linked to MEF2D or PD (Figure 1). Some of them are likely to form an interconnected regulatory network which links together several key subcellular organelles and processes already implicated in PD. They, therefore, provide the basis for further investigation of the molecular basis of $\mathrm{PD}$

\section{REFERENCES}

Ahuja, H. S., Zhu, Y., and Zakeri, Z. (1997). Association of cyclindependent kinase 5 and its activator p35 with apoptotic cell death. Dev. Genet. 21, 258-267.

Alam, Z. I., Daniel, S. E., Lees, A. J., Marsden, D. C., Jenner, P., and Halliwell, B. (1997a). A generalised increase in protein carbonyls in the brain in Parkinson's but not incidental Lewy body disease. J. Neurochem. 69, 1326-1329.

Alam, Z. I., Jenner, A., Daniel, S. E., Lees, A. J., Cairns, N., Marsden, C. D., Jenner, P., and Halliwell, B. (1997b). Oxidative DNA damage in the parkinsonian brain: an apparent selective increase in 8hydroxyguanine levels in substantia nigra. J. Neurochem. 69, 1196-1203.

Alegre-Abarrategui, J., Christian, H., Lufino, M. M., Mutihac, R., Venda, L. L., Ansorge, O., and WadeMartins, R. (2009). LRRK2 regulates autophagic activity and localizes to specific membrane microdomains in a novel human genomic reporter cellular model. Hum. Mol. Genet. 18, 4022-4034.

Amo, T., Sato, S., Saiki, S., Wolf, A. M., Toyomizu, M., Gautier, C. A., Shen, J., Ohta, S., and Hattori, N. (2011). Mitochondrial membrane potential decrease caused by loss of PINK1 is not due to proton leak, but to respiratory chain defects. Neurobiol. Dis. $41,111-118$

Bijur, G. N., and Jope, R. S. (2001). Proapoptotic stimuli induce nuclear accumulation of glycogen synthase kinase-3 beta. J. Biol. Chem. 276, 37436-37442.

Braak, H., Del Tredici, K., Rub, U., de Vos, R. A., Jansen Steur, E. N., and Braak, E. (2003). Staging of brain pathology related to sporadic Parkinson's disease. Neurobiol. Aging 24, 197-211.

Brown, E. J., Albers, M. W., Shin, T. B., Ichikawa, K., Keith, C. T., Lane, W. S., and Schreiber, S. L. (1994). A mammalian protein targeted by G1arresting rapamycin-receptor complex. Nature 369, 756-758.

Buschbeck, M., and Ullrich, A. (2005). The unique C-terminal tail of the mitogen-activated protein kinase
ERK5 regulates its activation and nuclear shuttling. J. Biol. Chem. 280, 2659-2667.

Cavanaugh, J. E., Ham, J., Hetman, M., Poser, S., Yan, C., and Xia, Z. (2001). Differential regulation of mitogenactivated protein kinases ERK1/2 and ERK5 by neurotrophins, neuronal activity, and cAMP in neurons. J. Neurosci. 21, 434-443.

Chae, T., Kwon, Y. T., Bronson, R., Dikkes, P., Li, E., and Tsai, L. H. (1997). Mice lacking p35, a neuronal specific activator of $\mathrm{Cdk} 5$, display cortical lamination defects, seizures, and adult lethality. Neuron $18,29-42$.

Chen, J., Zheng, X. F., Brown, E. J., and Schreiber, S. L. (1995). Identification of an 11-kDa FKBP12-rapamycinbinding domain within the $289-\mathrm{kDa}$ FKBP12-rapamycin-associated protein and characterization of a critical serine residue. Proc. Natl. Acad. Sci. U.S.A. 92, 4947-4951.

Chiu, M. I., Katz, H., and Berlin, V. (1994). RAPT1, a mammalian homolog of yeast Tor, interacts with the FKBP12/rapamycin complex. Proc. Natl. Acad. Sci. U.S.A. 91, 12574-12578.

Chong, Z. Z., Shang, Y. C., Zhang, L., Wang, S., and Maiese, K. (2010). Mammalian target of rapamycin: hitting the bull's-eye for neurological disorders. Oxid. Med. Cell. Longev. 3, 374-391.

Collier, T. J., Kanaan, N. M., and Kordower, J. H. (2011). Ageing as a primary risk factor for Parkinson's disease: evidence from studies of nonhuman primates. Nat. Rev. Neurosci. $12,359-366$.

Cookson, M. R. (2010). The role of leucine-rich repeat kinase 2 (LRRK2) in Parkinson's disease. Nat. Rev. Neurosci. 11, 791-797.

Cross, D. A., Alessi, D. R., Cohen, P., Andjelkovich, M., and Hemmings, B. A. (1995). Inhibition of glycogen synthase kinase- 3 by insulin medi785-789.

Dauer, W., and Przedborski, S. (2003). Parkinson's disease: mechanisms and models. Neuron 39, 889-909.

Devine, M. J., Plun-Favreau, H., and Wood, N. W. (2011). Parkinson's ated by protein kinase B. Nature 378 ,

pathogenesis and provide novel targets such as MEF2 for the development of new therapeutic strategies.

\section{ACKNOWLEDGMENTS}

This work was supported in part by NIH grants ES015317 (Zixu Mao), AG023695 (Zixu Mao), NS048254 (Zixu Mao), ES0167310002 (Zixu Mao), and Michael J. Fox Foundation (Zixu Mao).

disease and cancer: two wars, one front. Nat. Rev. Cancer 11, 812-823. Dexter, D. T., Carter, C. J., Wells, F. R., Javoy-Agid, F., Agid, Y., Lees, A., Jenner, P., and Marsden, C. D. (1989). Basal lipid peroxidation in substantia nigra is increased in Parkinson's disease. J. Neurochem. 52, 381-389.

D’Mello, S. R., Galli, C., Ciotti, T., and Calissano, P. (1993). Induction of apoptosis in cerebellar granule neurons by low potassium: inhibition of death by insulin-like growth factor I and cAMP. Proc. Natl. Acad. Sci. U.S.A. 90, 10989-10993.

Domin, J., and Waterfield, M. D. (1997). Using structure to define the function of phosphoinositide 3-kinase family members. FEBS Lett. 410, 91-95.

Drolet, R. E., Sanders, J. M., and Kern, J. T. (2011). Leucine-rich repeat kinase 2 (LRRK2) cellular biology: a review of recent advances in identifying physiological substrates and cellular functions. J. Neurogenet. 25, 140-151.

Elbaz, A., and Moisan, F. (2008). Update in the epidemiology of Parkinson's disease. Curr. Opin. Neurol. 21, 454-460.

Elbaz, A., and Tranchant, C. (2007). Epidemiologic studies of environmental exposures in Parkinson's disease. $J$. Neurol. Sci. 262, 37-44.

Embi, N., Rylatt, D. B., and Cohen, P. (1980). Glycogen synthase kinase-3 from rabbit skeletal muscle. Separation from cyclic-AMP-dependent protein kinase and phosphorylase kinase. Eur. J. Biochem. 107, 519-527.

English, J. M., Pearson, G., Baer, R., and Cobb, M. H. (1998). Identification of substrates and regulators of the mitogen-activated protein kinase ERK5 using chimeric protein kinases. J. Biol. Chem. 273, 3854-3860.

English, J. M., Vanderbilt, C. A., Xu, S., Marcus, S., and Cobb, M. H. (1995). Isolation of MEK5 and differential expression of alternatively spliced forms. J. Biol. Chem. 270, 28897-28902

Fingar, D. C., and Blenis, J. (2004). Target of rapamycin (TOR): an integrator of nutrient and growth factor signals and coordinator of cell growth and cell cycle progression. Oncogene 23, 3151-3171.

Floor, E., and Wetzel, M. G. (1998). Increased protein oxidation in human substantia nigra pars compacta in comparison with basal ganglia and prefrontal cortex measured with an improved dinitrophenylhydrazine assay. J. Neurochem. 70, 268-275.

Franklin, J. L., and Johnson, E. M. Jr. (1992). Suppression of programmed neuronal death by sustained elevation of cytoplasmic calcium. Trends Neurosci. 15, 501-508.

Fu, W. Y., Wang, J. H., and Ip, N. Y. (2002). Expression of Cdk5 and its activators in NT2 cells during neuronal differentiation. J. Neurochem. 81, 646-654.

Gao, C., Negash, S., Wang, H. S., Ledee, D., Guo, H., Russell, P., and Zelenka, P. (2001). Cdk5 mediates changes in morphology and promotes apoptosis of astrocytoma cells in response to heat shock. J. Cell Sci. 114(Pt 6), 1145-1153.

Geisler, S., Holmström, K. M., Skujat, D., Fiesel, F. C., Rothfuss, O. C., Kahle, P. J., and Springer, W. (2010). PINK1/Parkin-mediated mitophagy is dependent on VDAC1 and p62/SQSTM1. Nat. Cell Biol. 12, 119-131.

Ghosh, A., and Greenberg, M. E. (1995). Calcium signaling in neurons: molecular mechanisms and cellular consequences. Science 268, 239-247.

Gomez-Suaga, P., Luzon-Toro, B., Churamani, D., Zhang, L., Bloor-Young, D., Patel, S., Woodman, P. G., Churchill, G. C., and Hilfiker, S. (2012). Leucine-rich repeat kinase 2 regulates autophagy through a calcium-dependent pathway involving NAADP. Hum. Mol. Genet. 21, 511-525.

Gong, X., Tang, X., Wiedmann, M., Wang, X., Peng, J., Zheng, D., Blair, L. A., Marshall, J., and Mao, Z. (2003). Cdk5-mediated inhibition of the protective effects of transcription factor MEF2 in neurotoxicityinduced apoptosis. Neuron 38, 33-46. 
Grant, P., Sharma, P., and Pant, H. C. (2001). Cyclin-dependent protein kinase $5(\mathrm{Cdk} 5)$ and the regulation of neurofilament metabolism. Eur. J. Biochem. 268, 1534-1546.

Graves, J. D., Draves, K. E., Craxton, A., Saklatvala, J., Krebs, E. G., and Clark, E. A. (1996). Involvement of stressactivated protein kinase and $\mathrm{p} 38$ mitogen-activated protein kinase in mIgM-induced apoptosis of human B lymphocytes. Proc. Natl. Acad. Sci. U.S.A. 93, 13814-13818.

Han, J., Jiang, Y., Li, Z., Kravchenko, V. V., and Ulevitch, R. J. (1997). Activation of the transcription factor MEF2C by the MAP kinase p38 in inflammation. Nature 386, 296-299.

Han, J., Lee, J. D., Bibbs, L., and Ulevitch, R. J. (1994). A MAP kinase targeted by endotoxin and hyperosmolarity in mammalian cells. Science $265,808-811$.

Han, J., Lee, J. D., Tobias, P. S., and Ulevitch, R. J. (1993). Endotoxin induces rapid protein tyrosine phosphorylation in $70 \mathrm{Z} / 3$ cells expressing CD14. J. Biol. Chem. 268, 25009-25014.

Hara, K., Maruki, Y., Long, X., Yoshino, K., Oshiro, N., Hidayat, S., Tokunaga, C., Avruch, J., and Yonezawa, K. (2002). Raptor, a binding partner of target of rapamycin (TOR), mediates TOR action. Cell 110, 177-189.

Hay, N., and Sonenberg, N. (2004). Upstream and downstream of mTOR. Genes Dev. 18, 1926-1945.

Hayashi, M., Fearns, C., Eliceiri, B., Yang, Y., and Lee, J. D. (2005). Big mitogen-activated protein kinase 1/extracellular signal-regulated kinase 5 signaling pathway is essential for tumor-associated angiogenesis. Cancer Res. 65, 7699-7706.

Healy, D. G., Falchi, M., O'Sullivan, S. S., Bonifati, V., Durr, A., Bressman, S., Brice, A., Aasly, J., Zabetian, C. P., Goldwurm, S., Ferreira, J. J., Tolosa, E., Kay, D. M., Klein, C., Williams, D. R., Marras, C., Lang, A. E., Wszolek, Z. K., Berciano, J., Schapira, A. H., Lynch, T., Bhatia, K. P., Gasser, T., Lees, A. J., Wood, N. W., and International LRRK2 Consortium. (2008). Phenotype, genotype, and worldwide genetic penetrance of LRRK2-associated Parkinson's disease: a case-control study. Lancet Neurol. 7, 583-590.

Hellmich, M. R., Pant, H. C., Wada, E., and Battey, J. F. (1992). Neuronal cdc2-like kinase: a cdc2-related protein kinase with predominantly neuronal expression. Proc. Natl. Acad. Sci. U.S.A. 89, 10867-10871.
Hetman, M., Cavanaugh, J. E., Kimelman, D., and Xia, Z. (2000). Role of glycogen synthase kinase-3beta in neuronal apoptosis induced by trophic withdrawal. J. Neurosci. 20, 2567-2574.

Hresko, R. C., and Mueckler, M. (2005). mTOR.RICTOR is the Ser473 kinase for Akt/protein kinase B in 3T3L1 adipocytes. J. Biol. Chem. 280, 40406-40416.

Hughes, K., Nikolakaki, E., Plyte, S. E., Totty, N. F., and Woodgett, J. R. (1993). Modulation of the glycogen synthase kinase-3 family by tyrosine phosphorylation. EMBO J. 12, 803-808.

Jacinto, E., Loewith, R., Schmidt, A., Lin, S., Rüegg, M. A., Hall, A., and Hall, M. N. (2004). Mammalian TOR complex 2 controls the actin cytoskeleton and is rapamycin insensitive. Nat. Cell Biol. 6, 1122-1128.

Jiang, Y., Gram, H., Zhao, M., New, L., Gu, J., Feng, L., Di Padova, F., Ulevitch, R. J., and Han, J. (1997). Characterization of the structure and function of the fourth member of p38 group mitogen-activated protein kinases, p38delta. J. Biol. Chem. 272, 30122-30128.

Jung, C. H., Ro, S. H., Cao, J., Otto, N. M., and Kim, D. H. (2010). mTOR regulation of autophagy. FEBS Lett. 584, 1287-1295.

Kalinderi, K., Fidani, L., Katsarou, Z., Clarimon, J., Bostantjopoulou, S., and Kotsis, A. (2011). GSK3beta polymorphisms, MAPT H1 haplotype and Parkinson's disease in a Greek cohort. Neurobiol. Aging 32, 546.e1-546.e5.

Kamakura, S., Moriguchi, T., and Nishida, E. (1999). Activation of the protein kinase ERK5/BMK1 by receptor tyrosine kinases. Identification and characterization of a signaling pathway to the nucleus. J. Biol. Chem. 274, 26563-26571.

Kato, Y., Kravchenko, V. V., Tapping, R. I., Han, J., Ulevitch, R. J., and Lee, J. D. (1997). BMK1/ERK5 regulates serum-induced early gene expression through transcription factor MEF2C. $E M B O ~ J . ~ 16$, 7054-7066.

Kato, Y., Tapping, R. I., Huang, S., Watson, M. H., Ulevitch, R. J., and Lee, J. D. (1998). Bmk1/Erk5 is required for cell proliferation induced by epidermal growth factor. Nature 395, 713-716.

Kaytor, M. D., and Orr, H. T. (2002). The GSK3 beta signaling cascade and neurodegenerative disease. Curr. Opin. Neurobiol. 12, 275-278.
Kim, D. H., Sarbassov, D. D., Ali, S. M., King, J. E., Latek, R. R., ErdjumentBromage, H., Tempst, P., and Sabatini, D. M. (2002). mTOR interacts with raptor to form a nutrientsensitive complex that signals to the cell growth machinery. Cell 110, 163-175.

Kim, E. K., and Choi, E. J. (2010). Pathological roles of MAPK signaling pathways in human diseases. Biochim. Biophys. Acta 1802 396-405.

Ko, J., Humbert, S., Bronson, R. T., Takahashi, S., Kulkarni, A. B., Li, E., and Tsai, L. H. (2001). p35 and p39 are essential for cyclindependent kinase 5 function during neurodevelopment. J. Neurosci. 21, 6758-6771.

Koh, P.-O. (2008). Melatonin prevents ischemic brain injury through activation of the mTOR/p70S6 kinase signaling pathway. Neurosci. Lett. 444, 74-78.

Koh, P.-O., Cho, J.-H., Won, C.-K., Lee, H.-J., Sung, J.-H., and Kim, M.-O. (2008). Estradiol attenuates the focal cerebral ischemic injury through mTOR/p70S6 kinase signaling pathway. Neurosci. Lett. 436 , 62-66.

Kunz, J., Henriquez, R., Schneider, U., Deuter-Reinhard, M., Movva, N. R. and Hall, M. N. (1993). Target of rapamycin in yeast, TOR2, is an essential phosphatidylinositol kinase homolog required for G1 progression. Cell 73, 585-596.

Kwok, J. B., Hallupp, M., Loy, C. T., Chan, D. K., Woo, J., Mellick, G. D., Buchanan, D. D., Silburn, P. A., Halliday, G. M., and Schofield, P. R. (2005). GSK3B polymorphisms alter transcription and splicing in Parkinson's disease. Ann. Neurol. 58 829-839.

Lagace, D. C., Benavides, D. R., Kansy, J. W., Mapelli, M., Greengard, P., Bibb, J. A., and Eisch, A. J. (2008). Cdk5 is essential for adult hippocampal neurogenesis. Proc. Natl. Acad. Sci. U.S.A. 105, 18567-18571.

Lee, J. D., Ulevitch, R. J., and Han, J. (1995). Primary structure of BMK1: a new mammalian map kinase. Biochem. Biophys. Res. Commun. 213, 715-724.

Lees, A. J., Hardy, J., and Revesz, T. (2009). Parkinson's disease. Lancet 373, 2055-2066.

Leifer, D., Krainc, D., Yu, Y. T., McDermott, J., Breitbart, R. E., Heng, J., Neve, R. L., Kosofsky, B., NadalGinard, B., and Lipton, S. A. (1993). MEF2C, a MADS/MEF2family transcription factor expressed in a laminar distribution in cerebral cortex. Proc. Natl. Acad. Sci. U.S.A. 90, 1546-1550.

Lew, J., Huang, Q. Q., Qi, Z., Winkfein, R. J., Aebersold, R., Hunt, T., and Wang, J. H. (1994). A brain-specific activator of cyclin-dependent kinase 5. Nature 371, 423-426.

Lew, J., Winkfein, R. J., Paudel, H. K., and Wang, J. H. (1992). Brain prolinedirected protein kinase is a neurofilament kinase which displays high sequence homology to p34cdc2. $J$. Biol. Chem. 267, 25922-25926.

Li, Z., Jiang, Y., Ulevitch, R. J., and Han, J. (1996). The primary structure of p 38 gamma: a new member of $\mathrm{p} 38$ group of MAP kinases. Biochem. Biophys. Res. Commun. 228, 334-340.

Lin, X., Parisiadou, L., Gu, X.-L., Wang, L., Shim, H., Sun, L., Xie, C., Long, C.-X., Yang, W.-J., Ding, J., Chen, Z. Z., Gallant, P. E., Tao-Cheng, J. H. Rudow, G., Troncoso, J. C., Liu, Z., Li, Z., and Cai, H. (2009). Leucine-rich repeat kinase 2 regulates the progression of neuropathology induced by Parkinson's-disease-related mutant $\alpha$-synuclein. Neuron 64, 807-827.

Liu, L., Cavanaugh, J. E., Wang, Y., Sakagami, H., Mao, Z., and Xia, Z. (2003). ERK5 activation of MEF2mediated gene expression plays a critical role in BDNF-promoted survival of developing but not mature cortical neurons. Proc. Natl. Acad. Sci. U.S.A. 100, 8532-8537.

Lucas, J. J., Hernandez, F., GomezRamos, P., Moran, M. A., Hen, R., and Avila, J. (2001). Decreased nuclear beta-catenin, tau hyperphosphorylation and neurodegeneration in GSK-3beta conditional transgenic mice. EMBO J. 20, 27-39.

MacLeod, D., Dowman, J., Hammond, R., Leete, T., Inoue, K., and Abeliovich, A. (2006). The familial parkinsonism gene LRRK2 regulates neurite process morphology. Neuron 52, 587-593.

Mao, Z., Bonni, A., Xia, F., Nadal-Vicens, M., and Greenberg, M. E. (1999). Neuronal activity-dependent cell survival mediated by transcription factor MEF2. Science 286, 785-790.

Marinissen, M. J., Chiariello, M., Pallante, M., and Gutkind, J. S. (1999). A network of mitogen-activated protein kinases links G proteincoupled receptors to the c-jun promoter: a role for c-Jun NH2terminal kinase, $\mathrm{p} 38 \mathrm{~s}$, and extracellular signal-regulated kinase 5. Mol. Cell. Biol. 19, 4289-4301.

Matsuda, N., Sato, S., Shiba, K., Okatsu, K., Saisho, K., Gautier, C. A., Sou, Y. S., Saiki, S., Kawajiri, S., Sato, F., Kimura, M., Komatsu, M., Hattori, N., and Tanaka, K. (2010). PINK1 
stabilized by mitochondrial depolarization recruits Parkin to damaged mitochondria and activates latent Parkin for mitophagy. J. Cell Biol. 189, 211-221.

Mertens, S., Craxton, M., and Goedert, M. (1996). SAP kinase-3, a new member of the family of mammalian stress-activated protein kinases. FEBS Lett. 383, 273-276.

Meyerson, M., Enders, G. H., Wu, C. L., Su, L. K., Gorka, C., Nelson, C., Harlow, E., and Tsai, L. H. (1992). A family of human cdc2-related protein kinases. ЕMBO J. 11, 2909-2917.

Miller, T. M., Tansey, M. G., Johnson, E. M. Jr., and Creedon, D. J. (1997). Inhibition of phosphatidylinositol 3-kinase activity blocks depolarization- and insulinlike growth factor I-mediated survival of cerebellar granule cells. $J$. Biol. Chem. 272, 9847-9853.

Mora, A., Sabio, G., Gonzalez-Polo, R. A., Cuenda, A., Alessi, D. R., Alonso, J. C., Fuentes, J. M., Soler, G., and Centeno, F. (2001). Lithium inhibits caspase 3 activation and dephosphorylation of PKB and GSK3 induced by $\mathrm{K}+$ deprivation in cerebellar granule cells. J. Neurochem. 78, 199-206.

Narendra, D., Tanaka, A., Suen, D. F., and Youle, R. J. (2008). Parkin is recruited selectively to impaired mitochondria and promotes their autophagy. J. Cell Biol. 183, 795-803.

Narendra, D. P., Jin, S. M., Tanaka, A., Suen, D.-F., Gautier, C. A., Shen, J., Cookson, M. R., and Youle, R. J. (2010). PINK1 is selectively stabilized on impaired mitochondria to activate parkin. PLoS Biol. 8, e1000298. doi:10.1371/journal.pbio. 1000298

Newhouse, K., Hsuan, S. L., Chang, S. H., Cai, B., Wang, Y., and Xia, Z. (2004). Rotenone-induced apoptosis is mediated by p38 and JNK MAP kinases in human dopaminergic SH-SY5Y cells. Toxicol. Sci. 79, 137-146.

Ohshima, T., Ward, J. M., Huh, C. G., Longenecker, G., Veeranna, Pant, H. C., Brady, R. O., Martin, L. J., and Kulkarni, A. B. (1996). Targeted disruption of the cyclin-dependent kinase 5 gene results in abnormal corticogenesis, neuronal pathology and perinatal death. Proc. Natl. Acad. Sci. U.S.A. 93, 11173-11178.

Okamoto, S., Krainc, D., Sherman, K., and Lipton, S. A. (2000). Antiapoptotic role of the p38 mitogenactivated protein kinase-myocyte enhancer factor 2 transcription factor pathway during neuronal differentiation. Proc. Natl. Acad. Sci. U.S.A. 97, 7561-7566.

Oppenheim, R. W. (1991). Cell death during development of the nervous system. Annu. Rev. Neurosci. 14, 453-501.

Paisán-Ruíz, C., Jain, S., Evans, E. W., Gilks, W. P., Simón, J., van der Brug, M., de Munain, A. L., Aparicio, S., Gil, A. M. N., Khan, N., Johnson, J., Martinez, J. R., Nicholl, D., Carrera, I. M., Pena, A. S., de Silva, R., Lees, A., Martí-Massó, J. F., Pérez-Tur, J., Wood, N. W., and Singleton, A. B. (2004). Cloning of the gene containing mutations that cause PARK8linked Parkinson's disease. Neuron 44, 595-600.

Pap, M., and Cooper, G. M. (1998). Role of glycogen synthase kinase3 in the phosphatidylinositol 3kinase/Akt cell survival pathway. $J$. Biol. Chem. 273, 19929-19932.

Patrick, G. N., Zukerberg, L., Nikolic, M., de la Monte, S., Dikkes, P., and Tsai, L. H. (1999). Conversion of p35 to p25 deregulates Cdk5 activity and promotes neurodegeneration. Nature 402, 615-622.

Pattingre, S., Espert, L., BiardPiechaczyk, M., and Codogno, P. (2008). Regulation of macroautophagy by mTOR and Beclin 1 complexes. Biochimie 90, 313-323.

Pearce, R. K., Owen, A., Daniel, S., Jenner, P., and Marsden, C. D. (1997). Alterations in the distribution of glutathione in the substantia nigra in Parkinson's disease. J. Neural Transm. 104, 661-677.

Plowey, E. D., Cherra, S. J. III, Liu, Y. J., and Chu, C. T. (2008). Role of autophagy in G2019S-LRRK2associated neurite shortening in differentiated SH-SY5Y cells. J. Neurochem. 105, 1048-1056.

Raingeaud, J., Gupta, S., Rogers, J. S., Dickens, M., Han, J., Ulevitch, R. J., and Davis, R. J. (1995). Proinflammatory cytokines and environmental stress cause $\mathrm{p} 38$ mitogenactivated protein kinase activation by dual phosphorylation on tyrosine and threonine. J. Biol. Chem. 270, 7420-7426.

Ramonet, D., Daher, J. P., Lin, B. M., Stafa, K., Kim, J., Banerjee, R., Westerlund, M., Pletnikova, O., Glauser, L., Yang, L., Liu, Y., Swing, D. A., Beal, M. F., Troncoso, J. C., McCaffery, J. M., Jenkins, N. A., Copeland, N. G., Galter, D., Thomas, B., Lee, M. K., Dawson, T. M., Dawson, V. L., and Moore, D. J. (2011). Dopaminergic neuronal loss, reduced neurite complexity and autophagic abnormalities in transgenic mice expressing G2019S mutant
LRRK2. PLoS ONE 6, el8568. doi:10.1371/journal.pone.0018568

Rampalli, S., Li, L., Mak, E., Ge, K., Brand, M., Tapscott, S. J., and Dilworth, F. J. (2007). p38 MAPK signaling regulates recruitment of Ash2L-containing methyltransferase complexes to specific genes during differentiation. Nat. Struct. Mol. Biol. 14, 1150-1156.

Roberts, O. L., Holmes, K., Müller J., Cross, D. A., and Cross, M. J. (2009). ERK5 and the regulation of endothelial cell function. Biochem. Soc. Trans. 37, 1254.

Rydel, R. E., and Greene, L. A. (1988). cAMP analogs promote survival and neurite outgrowth in cultures of rat sympathetic and sensory neurons independently of nerve growth factor. Proc. Natl. Acad. Sci. U.S.A. 85 1257-1261.

Rylatt, D. B., Aitken, A., Bilham, T., Condon, G. D., Embi, N., and Cohen, P. (1980). Glycogen synthase from rabbit skeletal muscle. Amino acid sequence at the sites phosphorylated by glycogen synthase kinase3 , and extension of the N-terminal sequence containing the site phosphorylated by phosphorylase kinase. Eur. J. Biochem. 107, 529-537.

Sabatini, D. M., Erdjument-Bromage, H., Lui, M., Tempst, P., and Snyder S. H. (1994). RAFT1: a mammalian protein that binds to FKBP12 in a rapamycin-dependent fashion and is homologous to yeast TORs. Cell 78 , 35-43.

Sarbassov, D. D., Ali, S. M., Kim, D. H., Guertin, D. A., Latek, R. R. Erdjument-Bromage, H., Tempst, P., and Sabatini, D. M. (2004). Rictor, a novel binding partner of mTOR, defines a rapamycin-insensitive and raptor-independent pathway that regulates the cytoskeleton. Curr. Biol. 14, 1296-1302.

Sarbassov, D. D., Ali, S. M., Sengupta, S., Sheen, J.-H., Hsu, P. P., Bagley, A. F., Markhard, A. L., and Sabatini, D. M. (2006). Prolonged rapamycin treatment inhibits mTORC2 assembly and Akt/PKB. Mol. Cell 22, 159-168.

Sato, S., and Hattori, N. (2011). Genetic mutations and mitochondrial toxins shed new light on the pathogenesis of Parkinson's disease. Parkinsons Dis. 2011, 1-7.

Segal, R. A., and Greenberg, M. E. (1996). Intracellular signaling pathways activated by neurotrophic factors. Annu. Rev. Neurosci. 19 463-489.

Seki, N., Takahashi, Y., Tomiyama, H., Rogaeva, E., Murayama, S., Mizuno, Y., Hattori, N., Marras, C., Lang, A. E., George-Hyslop, P. S., Goto, J., and Tsuji, S. (2011). Comprehensive mutational analysis of LRRK2 reveals variants supporting association with autosomal dominant Parkinson's disease. J. Hum. Genet. 56, 671-675.

Shalizi, A., Lehtinen, M., Gaudilliere, B., Donovan, N., Han, J., Konishi, Y., and Bonni, A. (2003). Characterization of a neurotrophin signaling mechanism that mediates neuron survival in a temporally specific pattern. $J$. Neurosci. 23, 7326-7336.

Sharma, P., Sharma, M., Amin, N. D., Albers, R. W., and Pant, H. C. (1999). Regulation of cyclindependent kinase 5 catalytic activity by phosphorylation. Proc. Natl. Acad. Sci. U.S.A. 96, 11156-11160

She, H., Yang, Q., Shepherd, K., Smith, Y., Miller, G., Testa, C., and Mao, Z. (2011). Direct regulation of complex I by mitochondrial MEF2D is disrupted in a mouse model of Parkinson disease and in human patients. J. Clin. Invest. 121, 930-940.

Sherer, T. B., Betarbet, R., Testa, C. M., Seo, B. B., Richardson, J. R., Kim, J. H., Miller, G. W., Yagi, T., Matsuno-Yagi, A., and Greenamyre, J. T. (2003). Mechanism of toxicity in rotenone models of Parkinson's disease. J. Neurosci. 23, 10756-10764.

Smith, D. S., Greer, P. L., and Tsai, L. H. (2001). Cdk5 on the brain. Cell Growth Differ. 12, 277-283.

Smith, P. D., Mount, M. P., Shree, R., Callaghan, S., Slack, R. S., Anisman, H., Vincent, I., Wang, X., Mao, Z., and Park, D. S. (2006). Calpainregulated $\mathrm{p} 35 / \mathrm{cdk} 5$ plays a central role in dopaminergic neuron death through modulation of the transcription factor myocyte enhancer factor 2. J. Neurosci. 26, 440-447.

Spillantini, M. G., Schmidt, M. L., Lee, V. M., Trojanowski, J. Q., Jakes, R., and Goedert, M. (1997). Alphasynuclein in Lewy bodies. Nature 388, 839-840.

Suzaki, Y., Yoshizumi, M., Kagami, S., Koyama, A. H., Taketani, Y., Houchi, H., Tsuchiya, K., Takeda, E., and Tamaki, T. (2002). Hydrogen peroxide stimulates c-Src-mediated big mitogen-activated protein kinase 1 (BMK1) and the MEF2C signaling pathway in $\mathrm{PC} 12$ cells: potential role in cell survival following oxidative insults. J. Biol. Chem. 277, 9614-9621.

Tanaka, T., Veeranna, Ohshima, T., Rajan, P., Amin, N. D., Cho, A., Sreenath, T., Pant, H. C., Brady, R. O., and Kulkarni, A. B. (2001). Neuronal cyclin-dependent kinase 5 activity is critical for survival. J. Neurosci. 21, 550-558. 
Tang, D., Yeung, J., Lee, K. Y., Matsushita, M., Matsui, H., Tomizawa, K., Hatase, O., and Wang, J. H. (1995). An isoform of the neuronal cyclin-dependent kinase 5 (Cdk5) activator. J. Biol. Chem. 270, 26897-26903.

Tang, X., Wang, X., Gong, X., Tong, M., Park, D., Xia, Z., and Mao, Z. (2005). Cyclin-dependent kinase 5 mediates neurotoxin-induced degradation of the transcription factor myocyte enhancer factor 2. J. Neurosci. 25, 4823-4834.

Tanner, C. M., and Aston, D. A. (2000). Epidemiology of Parkinson's disease and akinetic syndromes. Curr. Opin. Neurol. 13, 427-430.

Thacker, E. L., Chen, H., Patel, A. V., McCullough, M. L., Calle, E. E., Thun, M. J., Schwarzschild, M. A., and Ascherio, A. (2008). Recreational physical activity and risk of Parkinson's disease. Mov. Disord. 23 , 69-74.

Tsai, L. H., Delalle, I., Caviness, V. S. Jr., Chae, T., and Harlow, E. (1994). p35 is a neural-specific regulatory subunit of cyclin-dependent kinase 5 . Nature 371, 419-423.

Tsai, L. H., Takahashi, T., Caviness, V. S. Jr., and Harlow, E. (1993). Activity and expression pattern of cyclindependent kinase 5 in the embryonic mouse nervous system. Development 119, 1029-1040.

Tung, H. Y., and Reed, L. J. (1989). Purification and characterization of protein phosphatase 1I activating kinase from bovine brain cytosolic and particulate fractions. J. Biol. Chem. 264, 2985-2990.

Unoki, M., and Nakamura, Y. (2001). Growth-suppressive effects of $\mathrm{BPOZ}$ and EGR2, two genes involved in the PTEN signaling pathway. Oncogene 20, 4457-4465.

Valente, E. M., Abou-Sleiman, P. M., Caputo, V., Muqit, M. M., Harvey, K., Gispert, S., Ali, Z., Del Turco, D., Bentivoglio, A. R., Healy, D. G., Albanese, A., Nussbaum, R., González-Maldonado, R., Deller, T., Salvi, S., Cortelli, P., Gilks, W. P., Latchman, D. S., Harvey, R. J., Dallapiccola, B., Auburger, G., and Wood, N. W. (2004). Hereditary early-onset Parkinson's disease caused by mutations in PINK1. Science 304, 1158-1160.
Vives-Bauza, C., Zhou, C., Huang, Y., Cui, M., de Vries, R. L. A., Kim, J., May, J., Tocilescu, M. A., Liu, W., Ko, H. S., Magrané, J., Moore, D. J., Dawson, V. L., Grailhe, R., Dawson, T. M., Li, C., Tieu, K., and Przedborski, S. (2010). PINK1-dependent recruitment of Parkin to mitochondria in mitophagy. Proc. Natl. Acad. Sci. U.S.A. 107, 378-383.

Vogiatzi, T., Xilouri, M., Vekrellis, K., and Stefanis, L. (2008). Wild type alpha-synuclein is degraded by chaperone-mediated autophagy and macroautophagy in neuronal cells. $J$. Biol. Chem. 283, 23542-23556.

Wang, X., She, H., and Mao, Z. (2009). Phosphorylation of neuronal survival factor MEF2D by glycogen synthase kinase 3 in neuronal apoptosis. J. Biol. Chem. 284, 32619-32626.

Wang, X., Tang, X., Li, M., Marshall, J., and Mao, Z. (2005). Regulation of neuroprotective activity of myocyteenhancer factor 2 by cAMP-protein kinase A signaling pathway in neuronal survival. J. Biol. Chem. 280, 16705-16713.

Wider, C., Dickson, D. W., and Wszolek, Z. K. (2010). Leucine-rich repeat kinase 2 gene-associated disease: redefining genotype-phenotype correlation. Neurodegener. Dis. 7, 175-179.

Williams, A., Jahreiss, L., Sarkar, S., Saiki, S., Menzies, F. M., Ravikumar, B., and Rubinsztein, D. C. (2006). Aggregate-prone proteins are cleared from the cytosol by autophagy: therapeutic implications. Curr. Top. Dev. Biol. 76, 89-101.

Woodgett, J. R. (1990). Molecular cloning and expression of glycogen synthase kinase-3/factor A. EMBO J. 9, 2431-2438.

Xia, Z., Dickens, M., Raingeaud, J., Davis, R. J., and Greenberg, M. E. (1995). Opposing effects of ERK and JNK-p38 MAP kinases on apoptosis. Science 270, 1326-1331.

Xiong, Y., Coombes, C. E., Kilaru, A., Li, X., Gitler, A. D., Bowers, W. J., Dawson, V. L., Dawson, T. M., and Moore, D. J. (2010). GTPase activity plays a key role in the pathobiology of LRRK2. PLoS Genet. 6, e1000902. doi:10.1371/journal.pgen.1000902

$\mathrm{Xu}, \mathrm{Q}$, and $\mathrm{Wu}, \mathrm{Z}$. (2000). The insulin-like growth factorphosphatidylinositol 3-kinase-Akt signaling pathway regulates myogenin expression in normal myogenic cells but not in rhabdomyosarcoma-derived RD cells. J. Biol. Chem. 275, 36750-36757.

Yan, L., Carr, J., Ashby, P. R., Murry-Tait, V., Thompson, C., and Arthur, J. S. (2003). Knockout of ERK5 causes multiple defects in placental and embryonic development. BMC Dev Biol. 3, 11. doi:10.1186/1471-213X3-11

Yang, C. C., Ornatsky, O. I., McDermott, J. C., Cruz, T. F., and Prody, C. A. (1998). Interaction of myocyte enhancer factor 2 (MEF2) with a mitogen-activated protein kinase, ERK5/BMK1. Nucleic Acids Res. 26, 4771-4777.

Yang, Q., She, H., Gearing, M., Colla, E., Lee, M., Shacka, J. J., and Mao, Z. (2009). Regulation of neuronal survival factor MEF2D by chaperonemediated autophagy. Science 323, 124-127.

Yang, S. H., Galanis, A., and Sharrocks, A. D. (1999). Targeting of p38 mitogen-activated protein kinases to MEF2 transcription factors. $\mathrm{Mol}$. Cell. Biol. 19, 4028-4038.

Yu, Y. T., Breitbart, R. E., Smoot, L. B., Lee, Y., Mahdavi, V., and NadalGinard, B. (1992). Human myocytespecific enhancer factor 2 comprises a group of tissue-restricted MADS box transcription factors. Genes Dev. 6, 1783-1798

Zhang, Q., Ahuja, H. S., Zakeri, Z. F., and Wolgemuth, D. J. (1997). Cyclin-dependent kinase 5 is associated with apoptotic cell death during development and tissue remodeling. Dev. Biol. 183 , 222-233.

Zhao, M., New, L., Kravchenko, V. V., Kato, Y., Gram, H., di Padova, F., Olson, E. N., Ulevitch, R. J., and Han, J. (1999). Regulation of the MEF2 family of transcription factors by p38. Mol. Cell. Biol. 19, 21-30.

Zheng, M., Leung, C. L., and Liem, R. K. (1998). Region-specific expression of cyclin-dependent kinase 5 (cdk5) and its activators, p35 and p39, in the developing and adult rat central nervous system. J. Neurobiol. 35, 141-159.

Zhou, G., Bao, Z. Q., and Dixon, J. E. (1995). Components of a new human protein kinase signal transduction pathway. J. Biol. Chem. 270, 12665-12669.

Zhou, H., and Huang, S. (2010). The complexes of mammalian target of rapamycin. Curr. Protein Pept. Sci. 11, 409-424.

Zhu, J., Li, W., and Mao, Z. (2011). Cdk5: mediator of neuronal development, death and the response to DNA damage. Mech. Ageing Dev. 132, 389-394.

Zimprich, A., Biskup, S., Leitner, P., Lichtner, P., Farrer, M., Lincoln, S., Kachergus, J., Hulihan, M., Uitti, R. J., Calne, D. B., Stoessl, A. J., Pfeiffer, R. F., Patenge, N., Carbajal, I. C., Vieregge, P., Asmus, F., Müller-Myhsok, B., Dickson, D. W., Meitinger, T., Strom, T. M., Wszolek, Z. K., and Gasser, T. (2004). Mutations in LRRK2 cause autosomal-dominant parkinsonism with pleomorphic pathology. Neuron 44, 601-607.

Zukerberg, L. R., Patrick, G. N., Nikolic, M., Humbert, S., Wu, C. L., Lanier, L. M., Gertler, F. B., Vidal, M., Van Etten, R. A., and Tsai, L. H. (2000). Cables links Cdk5 and c-Abl and facilitates Cdk5 tyrosine phosphorylation, kinase upregulation, and neurite outgrowth. Neuron 26, 633-646.

Conflict of Interest Statement: The authors declare that the research was conducted in the absence of any commercial or financial relationships that could be construed as a potential conflict of interest.

Received: 06 April 2012; paper pending published: 03 May 2012; accepted: 10 May 2012; published online: 29 May 2012.

Citation: Yin Y, She H, Li W, Yang Q, Guo S and Mao Z (2012) Modulation of neuronal survival factor MEF2 by kinases in Parkinson's disease. Front. Physio. 3:171. doi: 10.3389/fphys.2012.00171 This article was submitted to Frontiers in Systems Biology, a specialty of Frontiers in Physiology.

Copyright (c) 2012 Yin, She, Li, Yang, Guo and Mao. This is an open-access article distributed under the terms of the Creative Commons Attribution Non Commercial License, which permits noncommercial use, distribution, and reproduction in other forums, provided the original authors and source are credited.
Research Topic:

From structural to molecular systems biology: experimental and computational approaches to unravel mechanisms of kinase activity regulation in cancer and neurodegeneration
Topic Editor:

Matteo Barberis,

Humboldt University Berlin, Germany;

Max Planck Institute for Molecular Genetics, Berlin, Germany 